\title{
Emprego de modelos gráficos na seleção de genitores de milho para hibridização e mapeamento genético
}

\author{
Use of graphic models in maize parental selection for hybridization and mapping \\ Eduardo Alano Vieira ${ }^{1}$ Paulo Dejalma Zimmer ${ }^{2}$ Antonio Costa de Oliveira $^{2}$
Fernando Irajá Félix de Carvalho ${ }^{2}$ Gaspar Malone $^{3}$ Giovani Benin $^{1}$
}

\section{RESUMO}

A dissimilaridade genética estimada por meio de marcadores moleculares, quando acompanhada de informações fenotípicas, é importante para a seleção de genótipos para o melhoramento e o mapeamento genético. Desta forma, os objetivos deste estudo foram: i) estimar a dissimilaridade genética entre 30 linhagens de milho contrastantes para a tolerância ao encharcamento; ii) selecionar genitores para mapeamento e melhoramento genético; iii) comparar diferentes métodos de visualização gráfica das distâncias. Foram utilizados 21 iniciadores de RAPD. A dissimilaridade genética foi estimada por meio do complemento do coeficiente de similaridade de Dice, posteriormente foi construído um dendrograma pelo método de agrupamento da distância média e calculado o coeficiente de correlação cofenética entre a matriz de dissimilaridade e o dendrograma gerado. $O$ complemento da matriz de similaridade foi submetido também à análise de componentes principais e de escala multidimensional. Para ambas as análises, foi testada a eficiência das projeções, por meio da correlação entre as distâncias originais e as representadas nos gráficos. As técnicas de agrupamento não revelaram um bom ajuste entre as distâncias apresentadas graficamente e a matriz original de distâncias, com correlações de 0,70, 0,53 e 0,75 para o dendrograma, componentes principais e análise de escala multidimensional, respectivamente. Dentre as técnicas de agrupamento empregadas, a que atendeu de forma mais precisa aos objetivos do trabalho foi a análise multidimensional, uma vez que esta, além de apresentar a maior correlação com a matriz original de distâncias, preservou as distâncias entre todos os pares de genótipos. Além disso, esta técnica é a mais indicada quando o objetivo do trabalho é a definição de cruzamentos, pois ela permite uma observação mais fácil das distâncias entre todos os pares de genótipos.
Palavras-chave: Zea mays, resistência ao encharcamento, técnicas de agrupamento.

\section{ABSTRACT}

Associating phenotypic to molecular data can be a powerful tool for the selection of parental genotypes for breeding and mapping purposes. Thus, the objectives of the study were: i) to estimate the genetic dissimilarity among 30 maize inbred lines (15 tolerant and 15 sensitive to flooding); ii) to select potential parents for mapping and breeding; iii) to compare the efficiency of different graphical models in displaying the calculated distances. A total of 21 RAPD primers were used for the estimation of genetic dissimilarity. The genetic dissimilarity was obtained according to the complement of Dice similarity coefficient, clustering procedure was performed by the average linkage method and the cophenetic coefficient was obtained. The complement of Dice similarity coefficient was subjected to principal components and multidimensional scale analyses, and the output efficiency was tested by the correlation between the original distances and those presented in the graphs. The clustering techniques did not reveal a perfect agreement with the original matrix, with correlations of $0.70,0.53$ and 0.75 for the dendrogram, principal components and multidimensional scale analyses, respectively. Among the tested techniques employed, multidimensional scale analyses gave more precise outputs, since this technique showed higher agreement with the original distance matrix, and preserved distances between all genotype pairs. Besides, this technique is the most indicated when the objective is to plan crosses, since it displays the distances between genotype pairs.

Key words: Zea mays, flooding tolerance, clustering techniques.

${ }^{1}$ Programa de Pós-graduação em Agronomia da Universidade Federal de Pelotas (UFPel), RS, Brasil.

${ }^{2}$ Departamento de Fitotecnia da Faculdade de Agronomia Eliseu Maciel da UFPel, CP 354, 96010-900, Pelotas, RS, Brasil. Email:dejalma@msn.com. Autor para correspondência.

${ }^{3}$ Programa de Pós-graduação em Ciência e Tecnologia de Sementes da UFPel, Pelotas, RS, Brasil. 


\section{INTRODUÇÃO}

O conhecimento da distância genética entre genótipos de uma população de interesse é importante para um programa de melhoramento, pois permite a organização do germoplasma e uma amostragem mais eficiente de genótipos (NIENHUIS et al., 1993). Esta estimativa pode ser efetuada a partir de marcadores moleculares e/ou caracteres agronômicos (morfológicos), sendo que a primeira se destaca por não sofrer influência do ambiente. Entre as diversas técnicas de marcadores moleculares, o RAPD (polimorfismo de DNA amplificado ao acaso) merece destaque, pela rápida e fácil execução (CRUZ \& MILACH, 1998), podendo apresentar maior confiabilidade quando bandas consistentes entre duas extrações independentes são utilizadas (OLIVEIRA et al., 1996; YANG et al., 1996). Os marcadores de RAPD mostram um extraordinário potencial para investigar a variabilidade genética em espécies vegetais (PATZAK, 2001; PARENTONI et al., 2001; GICHUKI, et al., 2003).

Tal conhecimento, quando complementado por informações fenotípicas, permite a seleção de genitores para a formação de populações de melhoramento, uma vez que uma população originada do cruzamento de indivíduos superiores para o caráter de interesse e dissimilares geneticamente, terá grande probabilidade de dar origem a uma população com ampla variabilidade genética e com maior possibilidade de seleção de transgressivos para o caráter de interesse. Tal expectativa decorre do fato de que heterose e a capacidade específica de combinação entre dois genitores dependem da existência de dominância no controle do caráter e da presença de dissimilaridade entre os genótipos (FALCONER \& MACKAY, 1996). Além do que, é possível que genótipos geneticamente dissimilares, porém com fenótipos similares e superiores para o caráter de interesse, apresentem locos gênicos distintos controlando o caráter, que podem vir a ser reunidos em um terceiro genótipo, dando origem a um segregante transgressivo para o caráter sobre seleção (ação de genes complementares; CARVALHO et al., 2001).

A estimativa da diversidade genética por marcadores moleculares, quando acompanhada de informações fenotípicas, também é importante para a seleção de genótipos para o mapeamento genético. Isso porque permite a seleção de genótipos contrastantes e com alto nível de polimorfismo, que darão origem a populações de mapeamento altamente segregantes para o caráter de interesse e para os marcadores moleculares, o que facilitará a localização de marcadores associados aos locos controladores do caráter.
A tolerância ao encharcamento em milho se constitui em um caráter de grande importância para o sistema agrícola das regiões de várzea do sul do país, amplamente alicerçado, hoje no cúltivo de arroz irrigado e na criação extensiva de bovinos, ovinos e eqüinos. Mediante a realização de estudos mais aprofundados sobre este caráter, o milho poderá assumir uma importante alternativa de cultivo para a região. Estudos preliminares sugerem que há variabilidade genética para este caráter em milho (PORTO, 1997). O conhecimento genético molecular das linhagens disponíveis no programa de melhoramento poderá contribuir decisivamente para o aumento de eficiência dos estudos voltados ao entendimento dos mecanismos fisiológicos envolvidos, para o estabelecimento do número de genes e obtenção de marcadores moleculares associados ao caráter.

Os objetivos do presente estudo foram: i) estimar a dissimilaridade genética entre 30 linhagens de milho contrastantes para a tolerância ao encharcamento com o uso de marcadores RAPD; ii) selecionar genitores para obtenção de populações de mapeamento e de melhoramento genético; iii) comparar diferentes métodos de visualização gráfica das distâncias.

\section{MATERIAL E MÉTODOS}

As 30 linhagens de milho utilizadas no estudo foram obtidas a partir de cruzamentos entre linhas da Embrapa Clima Temperado e híbridos comerciais disponíveis no mercado. Nas primeiras gerações, os genótipos foram submetidos a testes de encharcamento (PORTO, 1997) e classificados em tolerantes (T) e suscetíveis (S).

O DNA foi extraído a partir de duas amostras foliares independentes para cada genótipo, conforme YANG et al. (1996), com a utilização do método de extração descrito por SAGHAI-MAROOF et al. (1984). A quantificação do DNA extraído foi realizada por eletroforese em gel de agarose $(0,8 \%)$ corado com brometo de etídeo (0,001\%), a concentração de DNA foi estimada através de comparação com o padrão conhecido do marcador de massa molecular de DNA de baixo peso (Invitrogen - Life Technologies).

A análise de RAPD seguiu o protocolo descrito por YANG et al. (1996). Os fragmentos amplificados foram separados eletroforeticamente em gel de agarose (1\%), corados com brometo de etídeo $(0,001 \%)$ e fotografados em um transluminador de luz ultravioleta. No trabalho, foram utilizados 21 iniciadores obtidos junto à “University of British Columbia” (UBC- 
$340,347,351,352,353,354,356,357,360,362,365,370$, $373,380,381,382,388,391,396,399$ e 400 ).

Os produtos das reações de amplificação (bandas), consistentes entre as duas extrações independentes, foram classificados conforme presença (1) e ausência (0). Os dados gerados a partir da análise de todos os indivíduos testados, foram utilizados para o cálculo da similaridade genética entre todos os pares de indivíduos, com o auxílio do programa computacional NTSYS pc 2.1 (ROHLF, 2000). No cálculo da similaridade genética (Sg), foi utilizado o coeficiente de Dice (DICE, 1945). A matriz de similaridade estimada foi transformada em uma matriz de dissimilaridade a partir do complemento da similaridade estimada ( $\mathrm{Dg}=1-\mathrm{Sg})$ e com base na matriz de dissimilaridade gerada foi construído um dendrograma por meio do método de agrupamento da distância média. Para a verificação do ajuste entre a matriz de dissimilaridade e o dendrograma, foi calculado o coeficiente de correlação cofenética (r), conforme SOKAL \& ROHLF (1962). A estabilidade estatística dos agrupamentos foi estimada pela análise de autoreamostragem com 1000 replicações através do programa computacional Winboot (YAP \& NELSON, 1996).

A matriz de dissimilaridade foi submetida também à análise de componentes principais e de escala multidimensional, para projeção das distâncias em um plano bidimensional. A eficiência da projeção das distâncias em um plano bidimensional, em ambos os métodos, foi estimada a partir da correlação entre as distâncias originais (Dij) e as representadas nos gráficos (Doij). Para as análises de escala multidimensional e de componentes principais, foi estimado também o nível de estresse (S) que mede o ajuste entre as distância na configuração bidimensional (Doij) e a distância original (Dij), da seguinte maneira:

$$
S=\sqrt{\frac{\sum_{i<} \sum_{j}(D o i j-D g i j)^{2}}{\sum_{i<} \sum_{j} D^{2} o i j}}
$$

Essas análises foram realizadas com o auxílio do programa computacional NTSYS pc 2.1 (ROHLF, 2000).

\section{RESULTADOS E DISCUSSÃO}

Os 21 iniciadores de RAPD utilizados no estudo geraram um total de 132 bandas, sendo que destas 105 (79,6\%) foram polimórficas, evidenciando a eficiência da técnica na deteç̧ão da variabilidade genética presente nas 30 linhagens de milho incluídas no trabalho. Resultado semelhante havia sido reportado para a cultura do milho por PARENTONI et al. (2001). Dentre as bandas polimórficas, cinco foram detectadas somente em genótipos suscetíveis ao encharcamento (nos iniciadores: UBC 353, 373, 380, 391 e 399); oito foram observadas apenas em genótipos tolerantes ao encharcamento (nos iniciadores: UBC-351, 357, 362, 381, 382, 388, 399 e 400). Estas bandas podem constituir marcadores com grande potencial para a diferenciação dos genótipos quanto à tolerância/suscetibilidade ao encharcamento. Além disso, podem vir a ser importantes no mapeamento genético, para a detecção de associação entre marcadores e locos controladores do caráter. Portanto, estas devem ser priorizadas quando do mapeamento genético, uma vez que existem evidências de que elas podem estar, pelo menos, parcialmente associadas ao caráter.

As técnicas de agrupamento empregadas não revelaram um bom ajuste entre as distâncias apresentadas graficamente e a matriz de dissimilaridade, com correlações de 0,70, 0,53 e 0,75 para o dendrograma, componentes principais e análise de escala multidimensional, respectivamente (Figuras 1 , 2 e 3). Isso porque, segundo SOKAL \& ROHLF (1962), somente valores de correlação cofenética superiores a 0,80 indicam um bom ajuste entre as matrizes originais de distância e as distâncias gráficas. Uma análise de divergência genética em espécies vegetais pode ser dividida de forma simplificada em seis fases: i) escolha dos genótipos a serem analisados; ii) obtenção dos dados e sistematização dos mesmos; iii) definição da medida de similaridade ou dissimilaridade a ser estimada; iv) escolha do método de agrupamento e/ou de dispersão gráfica a ser aplicado; v) verificação do grau de distorção provocado pelo método de agrupamento ou dispersão gráfica empregado e vi) interpretação dos resultados (HAIR et al., 1992; MANLY, 1994; CRUZ \& CARNEIRO, 2003). As quatro primeiras fases de uma análise de divergência genética, na maioria dos trabalhos publicados recentemente, vêm sendo bem executadas. Entretanto, alguns trabalhos pecam por não levarem em consideração a verificação do grau de distorção provocado pelo método de agrupamento ou dispersão gráfica empregados (GARCIA-MAS, et al., 2000; MANIFESTO et al., 2001); fase v) o que pode vir a comprometer a interpretação dos resultados (fase vi). Cabe ao pesquisador, quando de posse destes resultados, interpretá-los da melhor maneira possível, de acordo com os objetivos do seu trabalho, uma vez que, na maioria das vezes, é muito mais fácil a interpretação de uma figura representativa de uma técnica de agrupamento do que a análise de uma matriz de dissimilaridade. 
Os resultados evidenciaram inexistência de um padrão de distribuição dos genótipos de acordo com a tolerância ou suscetibilidade ao encharcamento (Figuras 1, 2 e 3). Muito embora tenha sido observado na figura 1 que dos sete agrupamentos que apresentaram um valor percentual de agrupamentos coincidentes superior a 30\%, após a realização de 1000 autoreamostragens, somente um foi formado por genótipos contrastantes quanto à tolerância ou suscetibilidade ao encharcamento, sendo este formado pelos genótipos 6S e 4T. Não foi observada, de forma clara, a formação de grupos distintos de constituições genéticas de acordo com o fenótipo, tendo sido observadas inúmeras sobreposições (grupos formados por genótipos T e S). Resultados como estes eram esperados uma vez que os marcadores RAPD acessam o genoma como um todo e não somente as regiões responsáveis pela manifestação do caráter. Caso fossem empregados marcadores específicos para as regiões controladoras da tolerância ou fossem avaliados caracteres fenotípicos associados a esta, poderia ser esperado um padrão de distribuição mais uniforme dos genótipos. Além disso, uma distribuição mais uniforme dos genótipos (de acordo com algum critério) também seria esperada, caso estes genótipos fossem oriundos de regiões distantes e com características distintas ou caso eles apresentassem um longo período de isolamento reprodutivo e/ou evolutivo (THOMPSON, et al., 1998; XU et al., 2000; SEMAN, et al., 2003).

Os baixos ajustes entre as distâncias originais e as observadas nas representações gráficas das técnicas de agrupamento (Figuras 1, 2 e 3) podem ter por base a hipótese da inexistência de um padrão

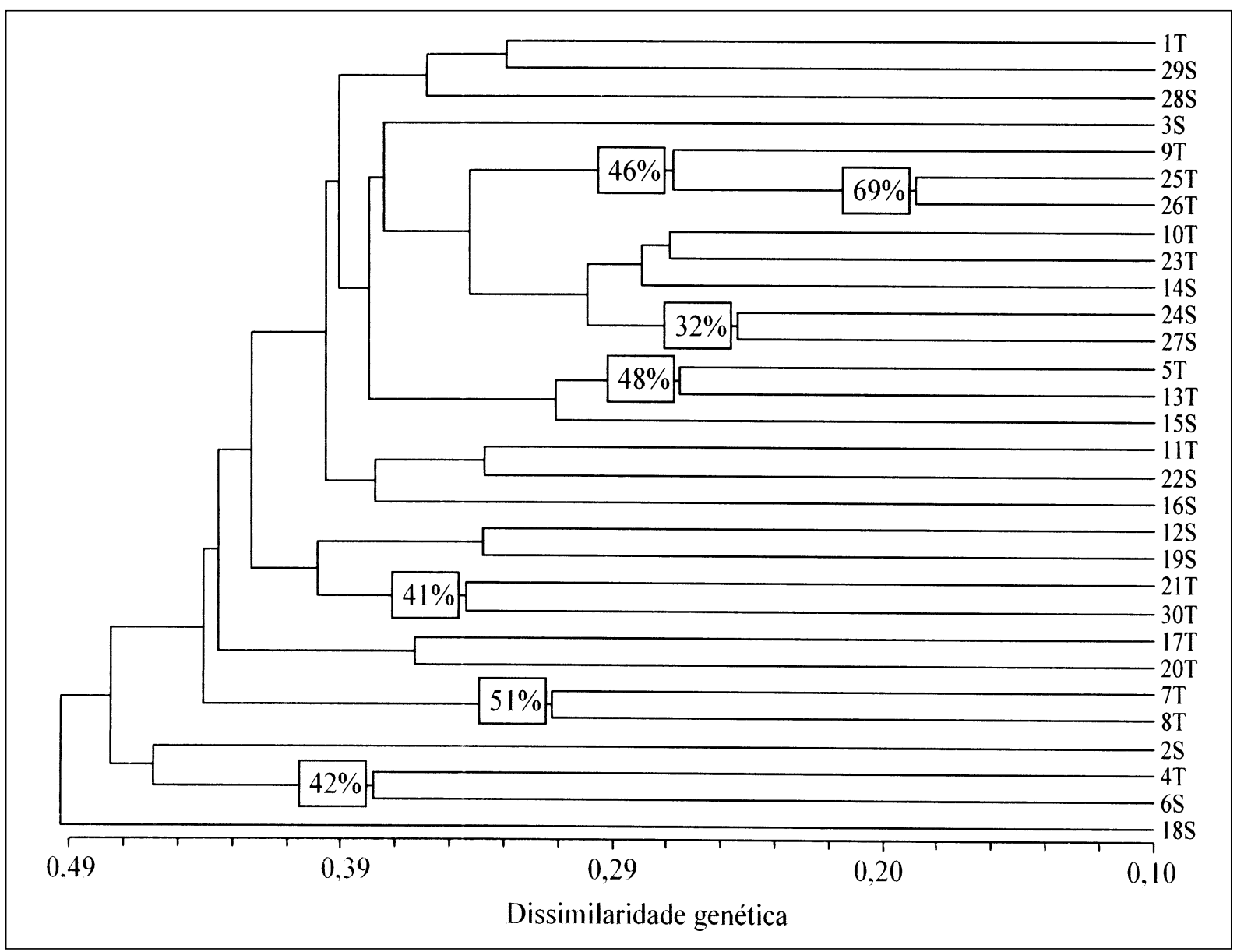

Figura 1 - Dendrograma de 30 linhagens de milho (enumeradas de 1 a 30) e classificadas como sensíveis (S) e tolerantes (T) ao encharcamento, obtido a partir da análise de RAPD utilizando o complemento da matriz de similaridade e o método de agrupamento da distância média. Os valores encontrados nos grupos indicam o valor percentual de vezes que os genótipos agruparam juntos em 1000 ciclos de análise de autoreamostragens utilizando o programa Winboot. O valor do coeficiente de correlação cofenética (r) é de 0,70. FAEM/UFPEL, Pelotas, 2004.

Ciência Rural, v.35, n.5, set-out, 2005. 


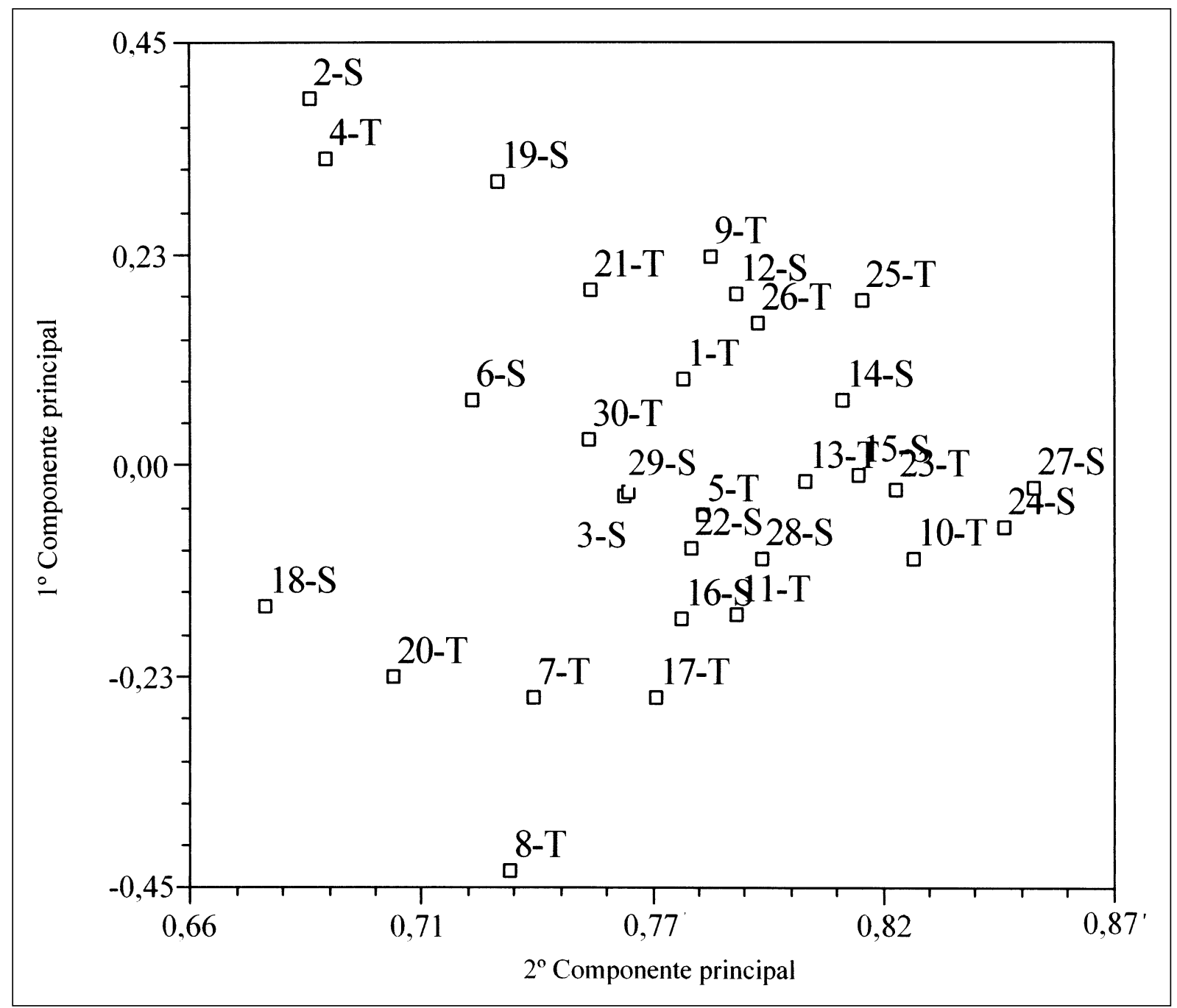

Figura 2 - Projeção em espaço bidimensional dos dois primeiros componentes principais obtidos a partir de marcadores RAPD, utilizando o complemento da matriz de similaridade de 30 linhagens de milho (enumeradas de 1 a 30) e classificadas como sensíveis (S) e tolerantes $(\mathrm{T})$ ao encharcamento. O valor da correlação entre as distâncias representadas no gráfico bidimensional e as distâncias originais (r) é de 0,53 e o coeficiente de estresse (S) =0,47. FAEM/UFPEL, Pelotas, 2004.

uniforme de distribuição dos genótipos, uma vez que para um ajuste elevado, seria necessário que os genótipos reunidos em um mesmo grupo apresentassem alta homogeneidade entre si e heterogeneidade com os genótipos dos demais grupos formados. Isso não foi observado no trabalho, pois nenhuma das técnicas de agrupamento foi eficiente, devido ao acúmulo de erros a cada agrupamento formado. Outro indicativo da inexistência de agrupamentos fortes (homogêneos) entre si e heterogêneos com os demais foi à alta similaridade apresentada pelos genótipos, uma vez que a grande maioria das constituições genéticas evidenciaram menos de 0,40 de dissimilaridade (Figura 1 e Tabela 1 ).
A técnica de análise de escala multidimensional foi a que apresentou o maior ajuste com a matriz de distâncias, e desta forma, pode ser considerada como a melhor técnica, para o agrupamento dos dados gerados. Entretanto, é necessário ressaltar que o nível de estresse (S) provocado pelo agrupamento foi elevado 25\% (Figura 3) valor este que está acima do grau máximo de aceitabilidade da técnica que é de 10\% (KRUSKAL, 1964). Comumente, a análise de escala multidimensional e os demais procedimentos de agrupamento comparam todos os pares de indivíduos através de medidas de similaridade ou de dissimilaridade entre os indivíduos; a análise de escala multidimensional se diferencia das

Ciência Rural, v.35, n.5, set-out, 2005. 


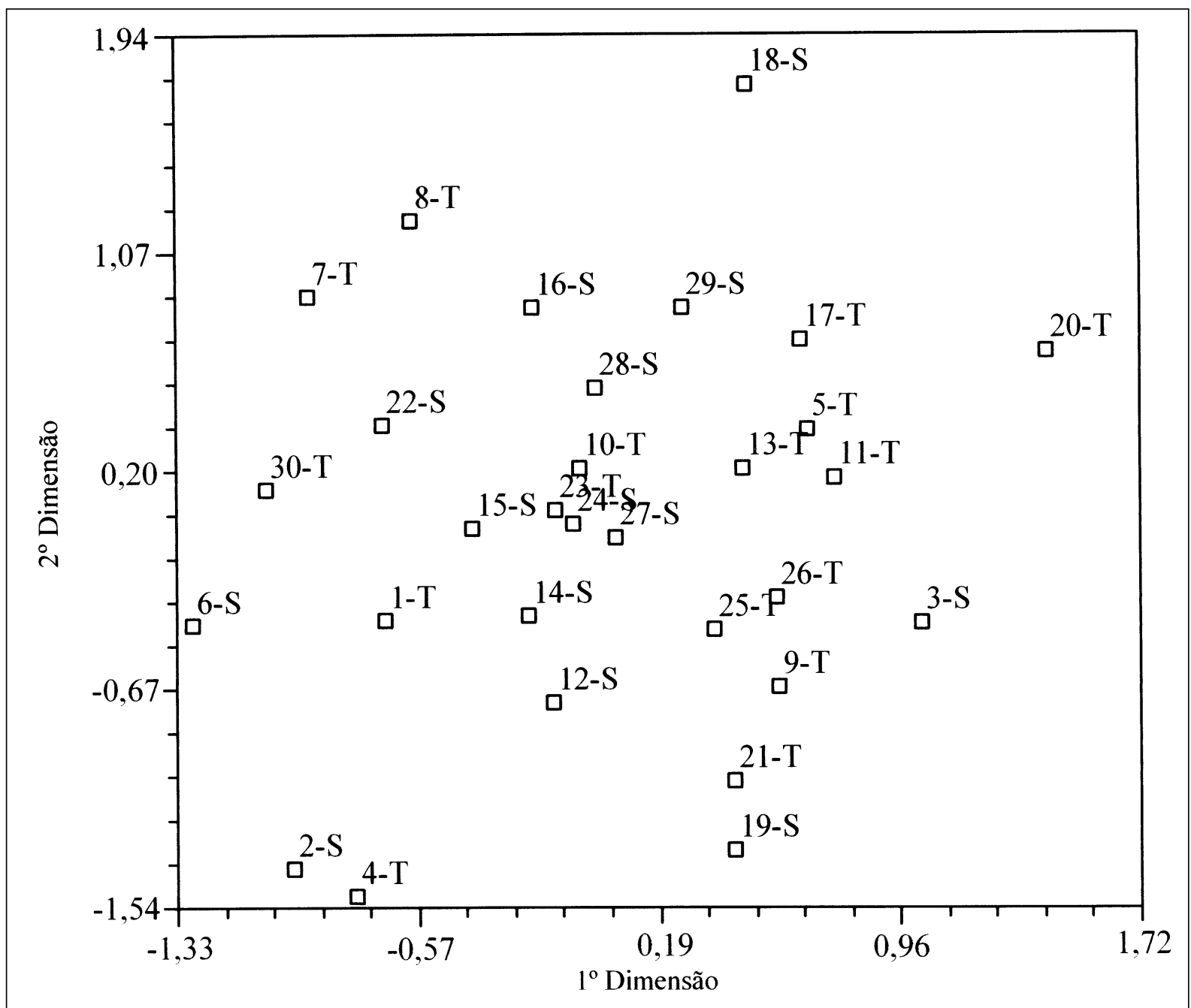

Figura 3 - Projeção em espaço bidimensional da escala multidimensional de 30 linhagens de milho (enumeradas de 1 a 30 ) e classificadas como sensíveis (S) e tolerantes (T) ao encharcamento, obtido a partir de marcadores RAPD utilizando o complemento do índice de similaridade. O valor da correlação entre as distâncias representadas no gráfico bidimensional e as distâncias originais (r) é de 0,75 e o coeficiente de estresse $(S)$ = 0,25. FAEM/UFPEL, Pelotas, 2004.

demais por procurar o maior ajuste entre a matriz original de distâncias por meio de uma análise de regressão. O melhor ajuste é então comparado com a distância original pela função estresse. As correlações entre os marcadores RAPD não podem mudar somente as distâncias, mas também a ordem das distâncias durante uma análise de escala multidimensional (HAIR et al., 1992; MANLY, 1994). A análise de escala multidimensional apresenta a propriedade de preservar de forma mais eficaz as menores distâncias entre os pontos do que a análise de componentes principais, que maximiza as variâncias e dá maior peso para as maiores distâncias.

Para a seleção de genótipos para hibridação artificial, visando à obtenção de uma população de melhoramento para seleção de constituições genéticas com alto nível de tolerância ao encharcamento, é necessário que os indivíduos selecionados apresentem alto nível de tolerância e sejam o mais dissimilar possível. Desta forma, aumenta-se a possibilidade de seleção de genótipos transgressivos, devido à ocorrência de heterose e a ação de genes complementares (FALCONER \& MACKAY, 1996; CARVALHO et al., 2001). Isso porque é esperado que genótipos com elevada tolerância ao encharcamento, porém dissimilares geneticamente, apresentem locos distintos controlando o caráter e por isso se combinem bem e apresentem a possibilidade de gerar boas populações de melhoramento. Para este propósito, destacam-se as combinações 4T X 8T e 20T X 4T (Tabela 1). 


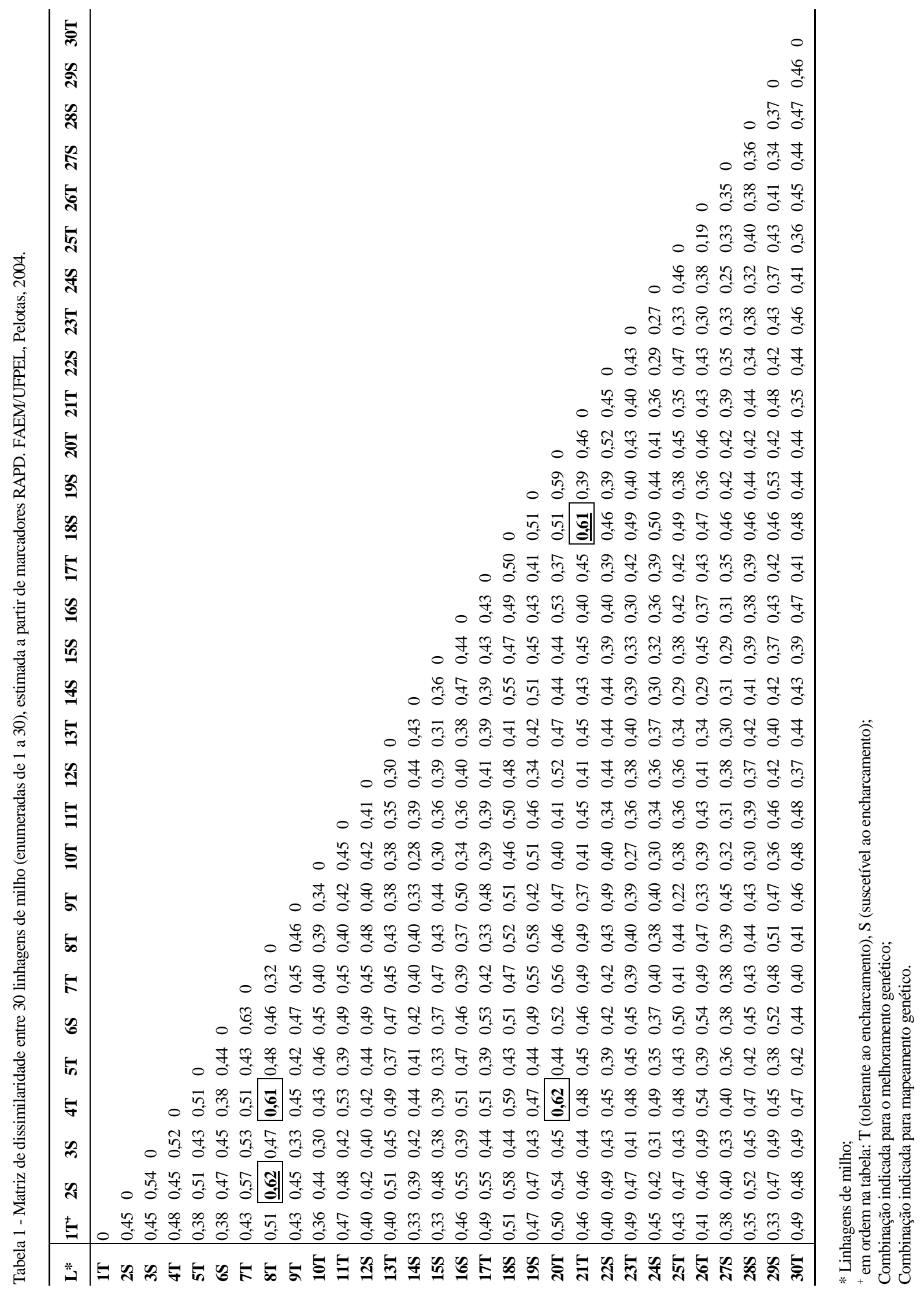

Ciência Rural, v.35, n.5, set-out, 2005. 
Para o mapeamento genético, é importante que os genitores sejam contrastantes para o caráter a ser mapeado e o mais dissimilar possível, a fim de maximizar a possibilidade de localização de marcadores associados aos locos controladores do caráter. Desta forma, destacam-se as combinações 18S X 21T e 2S X 8T (Tabela 1).

Dentre as técnicas de agrupamento empregadas, a que atendeu de forma mais precisa aos objetivos do trabalho foi a análise de escala multidimensional (Figura 3), uma vez que esta, além de apresentar a maior correlação com a matriz original de distâncias $(r=0,75)$, preservou as distâncias entre os pares de genótipos. Desta forma, esta técnica é a mais indicada quando o objetivo do trabalho é a definição de cruzamentos, pois ela permite uma observação mais fácil das distâncias entre todos os pares de genótipos. Por sua vez o dendrograma (Figura 1) não atendeu aos objetivos do trabalho, uma vez que não permitiu a identificação dos pares de genótipos mais dissimilares, pois a cada agrupamento formado acorre a perda da individualidade das distâncias entre os genótipos. A técnica de componentes principais (Figura 2) foi a que menos atendeu aos objetivos do trabalho, uma vez que foi a que expressou a menor correlação com a matriz de distâncias originais $(r=0,53)$ e também apresentou um alto valor de estresse ( $\mathrm{S}=0,47)$.

Embora os métodos de agrupamento utilizados neste trabalho não tenham apresentado uma boa correlação cofenética, ou seja, valores inferiores a 0,80, que segundo SOKAL \& ROHLF (1962), é o valor mínimo para a indicação de um bom ajuste entre as distâncias originais e as gráficas, isto não pode ser encarado como um descrédito em relação às metodologias. É necessário ter em mente que a eficiência do método de agrupamento (capacidade de apresentar graficamente os contrastes entre genótipos) depende da distribuição da variabilidade genética entre os genótipos testados. Portanto, previamente a decisão de qual método de agrupamento ser empregado, o pesquisador deverá considerar a acurácia dos mesmos. Dependendo da finalidade e dos objetivos do trabalho, podem ser realizadas inferências com base na matriz de distâncias, como no caso do presente trabalho, desde que o número de genótipos estudados não inviabilize a interpretação dos resultados. Este tipo de inferência não é possível de ser efetuada, quando o objetivo do trabalho é determinar a forma de distribuição da diversidade genética entre um grupo de genótipos ou populações, tornando necessária a utilização de algum método de agrupamento.

\section{AGRADECIMENTOS}

Os autores agradecem à Fundação de Amparo à Pesquisa do Estado do Rio Grande do Sul (FAPERGS), ao Conselho Nacional de Desenvolvimento Científico e Tecnológico (CNPq) e à Coordenação de Aperfeiçoamento de Pessoal de Nível Superior (CAPES) pelos auxílios financeiros recebidos e bolsas de pós-graduação e produtividade em pesquisa.

\section{REFERÊNCIAS}

CARVALHO, F.I.F. et al. Estimativas e implicações da herdabilidade como estratégia de seleção. Pelotas: UFPel, 2001. 99p.

CRUZ, C.D.; CARNEIRO, P.C.S. Modelos biométricos aplicados ao melhoramento de plantas. Viçosa: UFV, 2003. 585p. 2v.

CRUZ, R.P.; MILACH, S.C.K. Análise de RAPD. In: MILACH, S.C.K. Marcadores moleculares em plantas. Porto Alegre: Universidade Federal do Rio Grande do Sul, 1998. Cap.2. p.107116.

DICE, L.R. Measures of the amount of ecological association between species. Ecology, Washington, v.26, n.3, p.297-307, 1945.

FALCONER, D.S.; MACKAY, T.F. Introduction to quantitative genetics. 4 ed. Londres: Longman Group, 1996. 464p.

GARCIA-MAS, J. et al. Comparing AFLP, RAPD and RFLP markers for measuring genetic diversity in melon. Theoretical and Applied Genetics, New York, v.101, n.5-6, p.860-864, 2000.

GICHUKI, S.T. et al. Genetic diversity in sweetpotato [Ipomoea batatas (L.) Lam.] in relationship to geographic sources as assessed with RAPD markers. Genetic resources and crop evolution, Dordrecht, v.50, n.4, p.429-437, 2003.

HAIR, J.F. et al. Multivariate data analysis with readings. 3 ed. New York: Macmillan, 1992. 544p.

KRUSKAL, J.B. Multidimensional-scaling by optimizing goodness of fit to a non-metric hypothesis. Psychometrica, Williamsburg, v.29, n.1, p.1-27, 1964.

MANIFESTO, M.M. et al. Quantitative evaluation of genetic diversity in wheat germoplasm using molecular markers. Crop Science, Madison, v.41, n.3, p.682-690, 2001.

MANLY, B.F.J. Multivariate statistical methods: a primer. 2 ed. Boca Raton: Chapman \& Hall, 1994. 215p.

NIENHUIS, J. et al. Genetic similarity among Brassica oleracea genotypes as measured by restriction fragment length polymorphisms. Journal of the American Society for Horticultural Science, Alexandria, v.118, n.2, p.298-303, 1993.

OLIVEIRA, A.C. de. et al. Regional and racial specificities in sorghum germplasm assessed with DNA markers. Genome, v.39, n.3, p.579-587, 1996.

PARENTONI, S.N., et al. Heterotic groups based on yieldspecific combining ability data and phylogenetic relationship determined by RAPD markers for 28 tropical maize open 
pollinated varieties. Euphytica, Dordrecht, v.121, n.2, p.197208, 2001.

PATZAK, J. Comparison of RAPD, STS, ISSR and AFLP molecular methods for assessment of genetic diversity in hop (Humulus Iupulus L.). Euphytica, Dordrecht, v.121, n.1, p.9-18, 2001.

PORTO, M.P. Método de seleção de plantas de milho para tolerância ao encharcamento do solo. Pesquisa Agropecuária Gaúcha, Porto Alegre, v.3, n.2, p.187-190, 1997.

ROHLF, F. J. NTSYS-pc: numerical taxonomy and multivariate analysis system, version 2.1. New York: Exeter Software, 2000. 98p.

SAGHAI-MAROOF, M.A. et al. Ribosomal DNA spacer length polymorphism in barley: Mendelian inheritance, chromosome location and population dynamics. Proceedings of the national academy of sciences of the U.S.A, v.89, n.2, p.1477-1481, 1984.

SEMAN, K. et al. Genetic diversity and differentiation in Ethiopian populations of Phytolacca dodecandra as revealed by AFLP and RAPD analyses. Genetic resources and crop evolution, Dordrecht, v.50, n.6, p.649-661, 2003.

SOKAL, R.R.; ROHLF, F.J. The comparison of dendrograms by objective methods. Taxon, Berlin, v.11, n.1, p.30-40, 1962 .

THOMPSON, J.A. et al. Identification of diverse soybean germoplasm using RAPD markers. Crop Science, Madison, v.38, n.5, p.1348-1355, 1998.

$\mathrm{XU}$, R. et al. AFLP markers for characterizing the azuki bean complex. Crop Science, Madison, v.40, n.3, p.808-815, 2000 .

YANG, W.; et al. Comparison of DNA marker technologies in characterizing plant genome diversity: variability in Chinese sorghums. Crop Science, Madison, v.36, n.6, p.1669-1676, 1996.

YAP, I.V.; NELSON, R.J. Winboot: a program for performing bootstrap analysis of binary data to determine the confidence limits of UPGMA-based dendrograms. Manila: IRRI, 1996. 22p. 